\title{
Uma nova função da Defensoria Pública perante o Direito Internacional dos Direitos Humanos
}

\author{
Waltenberg Lima de Sá*
}

\section{Resumo}

O presente trabalho analisa uma das consequências doincrementodasfunçõesinstitucionais da Defensoria Pública pela Lei Complementar 132, de 7 de outubro de 2009, que torna explícita sua vocação para promover os direitos humanos. Discorre sobre a proteção dada aos refugiados pelo Direito Internacional dos Direitos Humanos, bem como seus reflexos no arcabouço jurídico brasileiro. Faz considerações sobre o devido processo legal para a análise da condição de refugiado dos estrangeiros que aportam no país. Constata a necessidade de assistência pela Defensoria Pública desde o início do procedimento perante a Polícia Federal, para tanto devendo obrigatoriamente ser comunicada de sua abertura.

\section{Palavras-chave}

Direitos humanos. Refugiados. Defensoria Pública. Devido processo legal. Deportação.

\section{Abstract}

This paper examines the consequences of an increase in institutional functions of the Public Defender by Complementary Law No. 132 of 7 October 2009, which makes explicit its purpose is to promote human rights. Discusses the protection afforded to refugees under international human rights and its impact in Brazilian legal. Raises questions regarding the due process for the analysis of refugee status of foreigners who arrive in the country. Notes the need for assistance by the Public Defender since the start of proceedings before the Federal Police, for that must always be notified of its opening.

Defensor Público Federal de $1^{\text {a }}$ Categoria e ex-Advogado da União.

\section{Keywords}

Human rights. Refugees. Public Defender. Due process. Deportation.

\section{Introdução}

O Direito Internacional dos Direitos Humanos já há algum tempo encontra terreno fértil no sistema jurídico brasileiro, mostrando-se um Estado de vanguarda na adesão aos tratados internacionais sobre a matéria e na absorção de seus preceitos pela legislação interna. No entanto, a implementação de tais tratados tem-se mostrado deficitária ante a insuficiência de instrumentos aptos a concretizá-los.

O presente artigo aborda a imprescindibilidade da assistência jurídica da Defensoria Pública aos estrangeiros irregulares. Para tanto, parte do Direito Internacional dos Refugiados como ramo do Direito Internacional dos Direitos Humanos, cujos preceitos foram incorporados pela ordem jurídica brasileira no delineamento do sistema de proteção dos refugiados.

Como corolário, a normatização interna que regula a matéria sofre os influxos dos princípios plasmados no referido sistema protetivo, dentre os quais o devido processo legal, a ser necessariamente observado quando do procedimento de deportação do estrangeiro irregular, bem como naquele destinado ao reconhecimento da sua condição de refugiado.

\section{0 Direito Internacional dos Refugiados como ramo do Direito Internacional dos Direitos Humanos}

Com o término da Segunda Guerra Mundial, sobretudoem razãodo holocaustoetodas as atrocidades das quais foram vítimas milhares de seres humanos em todo o planeta, os direitos humanos ascenderam no plano jurídico como forma de garantir a proteção de pessoas perseguidas em função de sua raça, religião, 
nacionalidade, opinião política ou pertencimento a determinado grupo social.

Por isso, o Direito internacional dos refugiados tem sido alvo de crescente preocupação por parte dos Estados. Atualmente, pode-se dizer que se encontra bem estruturado, sendo um dos ramos do Direito Internacional Público que mais se desenvolveram nas últimas décadas ${ }^{1}$.

Visando assegurar direitos aos refugiados condizentes com a dignidade da pessoa humana, após a $2^{a}$ Grande Guerra, a comunidade jurídica internacional passou a editar instrumentos normativos ratificados por vários Estados, destacando-se a Convenção relativa ao Estatuto dos Refugiados, de 1951, e o Protocolo sobre o Estatuto dos Refugiados, de 1967.

A definição de refugiado é trazida pela própria Convenção de 1951, que estabelece em seu art. 10, "A":

(...) o termo "refugiado" se aplicará a qualquer pessoa: ... que ... temendo ser perseguida por motivos de raça, religião, nacionalidade, grupo social ou opiniões políticas, encontra-se fora do país de sua nacionalidade e que não pode ou, em virtude desse temor, não valer-se da proteção desse país, ou que, se não tem nacionalidade encontra-se fora do país no qual tinha sua residência habitual em consequência de tais acontecimentos, não pode ou, devido ao referido temor, não quer voltar a ele.

Mais adiante se adotou a Convenção Americana sobre Direitos Humanos - Pacto de São José da Costa Rica (novembro de 1969), erigindo uma gama de direitos à categoria de direitos fundamentais, inerentes a todos os indivíduos por sua simples condição de ser humano.

Como expressão soberana de sua vontade e em um papel de liderança, o Estado brasileiro ratificou os instrumentos normativos acima citados e hoje é um dos países que mais têm recebido requerimentos de refúgio.

Com efeito, em 1960, foi o primeiro país do Cone Sul a ratificar a Convenção de 1951 sobre o Estatuto dos Refugiados (Decreto-legislativo 11, de 7/7/1960, promulgado pelo Decreto 50.215, de 28/1/1961, atualizado pelo Decreto 99.757, de 3/12/1990), ratificando, posteriormente, o Protocolo sobre o Estatuto dos Refugiados (Decreto 70.946, de 7/8/1972). Outrossim, em 1997 foi o primeiro país do Cone Sul a sancionar uma lei nacional de refúgio (Lei 9.474, de 22/7/1997).

No âmbito das Nações Unidas, o Alto Comissariado para os refugiados - UNHCR (Acnur em português), criado em 1951, é o órgão responsável para proteger e apoiar os refugiados de todo o mundo, por meio de repatriação voluntária, integração local e reassentamento em um terceiro país. O órgão realiza projetos de ajuda humanitária envolvendo Organizações Não Governamentais (ONG) em todo o mundo.

Atento à evolução do tema, pontifica Paulo Henrique Gonçalves Portela ${ }^{2}$ que "a matéria é objeto da atenção do Direito Internacional dos Refugiados, ramo do Direito das Gentes que visa a regular a proteção de pessoas nessa situação e a estabelecer o marco legal da cooperação internacional contra o problema".

\section{0 sistema de proteção dos refugiados no Brasil}

Conforme já frisado, o Brasil é um dos países que mais recebem estrangeiros e que mais declaram o status de refugiado. Consoante dados fornecidos pela Polícia Federal $^{3}$, existem 1.267.840 (um milhão, duzentos e sessenta e sete mil, oitocentos e quarenta) estrangeiros registrados no Brasil, localizados em maior quantidade nos seguintes Estados: São Paulo - 659.423, Rio de Janeiro - 268.936, Paraná - 66.040, Rio Grande do Sul - 60.807, Minas Gerais - 37.148 e Bahia - 27.088.

O Conare - Comitê Nacional para os Refugiados -, órgão da Administração Pública brasileira criado pela Lei 9.497/1997, é o responsável por receber os requerimentos edeterminar se os solicitantes reúnemas condições necessárias para serem reconhecidos como refugiados. Também é de sua atribuição a coordenação de políticas assistenciais aos refugiados, bem como a aprovação ou não dos programas e orçamentos anuais do Acnur.

As Cáritas Arquidiocesanas de São Paulo e do Rio de Janeiro oferecem assistência jurídica, orientação social, cursos de português e apoio na procura de empregos e moradia, além de participar das atividades e reuniões colegiadas do Conare.

Em que pese essa posição de vanguarda do Brasil no tratamento aos estrangeiros, a assistência jurídica 
era ofertada de maneira oficiosa, não alcançando os alienígenas de maneira ampla e invariável, visto que prestada por instituições paraestatais de forma esporádica e pontual, sequer abrangendo todo o território nacional.

Assim, verificava-se não haver uniformidade e constância, ou seja, regularidade decorrente da adoção sistemática de um procedimento apto a viabilizar a prestação de serviço público devidamente organizado para tanto. Ademais, não eram raros os casos em que os alienígenas não recebiam qualquer assistência jurídica, visto que os procedimentos eram ultimados sem serlhes oportunizado o auxílio de profissional habilitado.

Dessa forma, visando garantir a efetivação dos direitos previstos nos acordos internacionais ratificados pelo Brasil, o legislador pátrio aprovou a Lei Complementar 132, de 7 de outubro de 2009, elegendo a Defensoria Pública como a instituição vocacionada para a promoção dos direitos humanos, bem como incluindo nas suas funções institucionais a difusão e a conscientização dos direitos humanos e a legitimidade para representar aos sistemas internacionais de proteção dos direitos humanos, postulando perante seus órgãos ${ }^{4}$.

\section{0 devido processo legal para 0 reconhecimento da condição de refugiado}

\subsection{0 arcabouço jurídico internacional}

$\mathrm{O} \operatorname{artigo} 7^{\circ}, \$ 1^{\circ}$, da Convenção de Genebra relativa ao Estatuto dos Refugiados de 1951, prescreve que "ressalvadas as disposições mais favoráveis previstas por esta convenção, um Estado Contratante concederá aos refugiados o regime que concede aos estrangeiros em geral".

Mais adiante, a Convenção continua a estabelecer outros direitos aos refugiados, inclusive direitos de ordem processual, como o direito de ser tratado no mesmo patamar que um nacional e de obter assistência judiciária gratuita. É o que está previsto no artigo 16 da referida convenção, in verbis:

\section{Art. 16 - Direito de Propugnar em Juizo}

Qualquer refugiado terá, no território dos Estados Contratantes, livre e fácil acesso aos tribunais.
No Estado Contratante em que tem sua residência habitual, qualquer refugiado gozará do mesmo tratamento que um nacional, no que concerne ao acesso aos tribunais, inclusive a assistência judiciária e isenção de cautio judicatum solvi.

Nos Estados Contratantes outros que não aquele em que tem sua residência habitual, e no que concerne às questões mencionadas no parágrafo 2 , qualquer refugiado gozará do mesmo tratamento que um nacional do país no qual tem sua residência habitual.

Por sua vez, a Convenção Americana sobre Direitos Humanos (Pacto de São José da Costa Rica) de 1969, traz um extenso rol de direitos fundamentais inerentes a todo ser humano. Várias garantias judiciais foram concedidas, cuja inteligência é perfeitamente aplicável às garantias aos refugiados, vejamos:

\section{Artigo 8 - Garantias Judiciais}

1. Toda pessoa tem direito a ser ouvida, com as devidas garantias e dentro de um prazo razoável, por um juiz ou tribunal competente, independente e imparcial, estabelecido anteriormente por lei, na apuração de qualquer acusação penal formulada contra ela, ou para que se determinem seus direitos ou obrigações de natureza civil, trabalhista, fiscal ou de qualquer outra natureza.

2. Toda pessoa acusada de delito tem direito a que se presuma sua inocência enquanto não se comprove legalmente sua culpa. Durante o processo, toda pessoa tem direito, em plena igualdade, às seguintes garantias mínimas:

a) direito do acusado de ser assistido gratuitamente por tradutor ou intérprete, se não compreender ou não falar o idioma do juízo ou tribunal;

b) comunicação prévia e pormenorizada ao acusado da acusação formulada;

c) concessão ao acusado do tempo e dos meios adequados para a preparação de sua defesa;

d) direito do acusado de defender-se pessoalmente ou de ser assistido por um defensor de sua escolha e de comunicar-se, livremente e em particular, com seu defensor;

e) direito irrenunciável de ser assistido por um defensor proporcionado pelo Estado, remunerado ou não, segundo a legislação interna, se o acusado não se defender ele próprio nem nomear defensor dentro do prazo estabelecido pela lei;

Como se pode observar, a ordem jurídica internacional, sensível à situação fática vivenciada por 
aqueles que buscam refúgio, concedeu tratamento isonômico entre eles e os estrangeiros de forma geral.

\subsection{0 arcabouço jurídico brasileiro}

Conforme delineado acima, a proteção jurídica concedida aos estrangeiros tem evoluído no plano internacional no sentido de dar acolhida à efetividade dos direitos humanos. No Brasil, esta proteção tem égide, sobretudo, na Constituição Federal de 1988, nos tratados internacionais ratificados pelo país e na Lei 9.474/1997.

A nossa Constituição traz como um dos fundamentos da República Federativa do Brasil a dignidade da pessoa humana (art. $1^{\circ}$, III). No artigo $4^{\circ}$ elenca, dentre os princípios aplicados às relações internacionais, a prevalência dos direitos humanos (inciso II), a cooperação entre os povos para o progresso da humanidade (inciso IX) e a concessão de asilo político (inciso X). O artigo $5^{\circ}$ assegura também o contraditório e a ampla defesa em processo judicial e administrativo (inciso LV) e a prestação de assistência judiciária gratuita e integral aos necessitados (inciso LXXIV).

Nesse sentido, a lição de Liliana Lyra Jubilut ${ }^{5}$ :

Com base nesses princípios, pode-se afirmar que os alicerces da concessão do refúgio, vertente dos direitos humanos e espécie do direito de asilo são expressamente assegurados pela Constituição Federal de 1988, sendo ainda elevados à categoria de princípios de nossa ordem jurídica. (...) Dessa forma, além de obrigar o Brasil a zelar pelo respeito aos direitos humanos e a conceder asilo, assegurando mediatamente o refúgio, a Constituição Federal de 1988 estipula a igualdade de direitos entre os brasileiros e estrangeiros - incluindo-se os solicitantes de refúgio e os refugiados - do que se depreende que, salvo as exceções nele previstas, este documento coloca o ordenamento jurídico nacional, com todas as suas garantias e obrigações, à disposição dos estrangeiros que vêm buscar refúgio no Brasil. Desta feita, a Constituição Federal de 1988 traz as bases legais para a efetivação do instituto do refúgio no Brasil bem como dispõe sobre o tratamento jurídico a ser dispensado aos solicitantes de refúgio e refugiados - enquanto estrangeiros - no Brasil, mostrando-se consciente da importância do tema no atual momento da comunidade internacional.
Não é demais ressaltar que as referidas normas internacionais têm natureza jurídica de tratados de direitos humanos, revestindo-se do status de supralegalidade dentro da hierarquia normativa brasileira, revogando, assim, toda a legislação infraconstitucional que com elas sejam incompatíveis, como restou consolidado pelo Supremo Tribunal Federal no julgamento do HC 87.585 (Informativo 531). ${ }^{6}$

Ademais, com a aplicação do instituto do refúgio há a transferência da responsabilidade de proteção do indivíduo de um Estado para a comunidade internacional, por meio de um de seus membros. Tal fato ocorre em função de a Organização das Nações Unidas (ONU), apesar de possuir um órgão específico para tratar do tema, o Alto Comissariado das Nações Unidas para Refugiados (Acnur), não contar com um território que lhe seja próprio, no qual a proteção possa ser gozada.

Não bastasse, o Brasil optou por recepcionar o instituto do refúgio não só por meio da ratificação da Convenção de 1951 e do Protocolo de 1967, mas também pela adoção de uma lei específica: a Lei 9.474/1997, cujos termos decorreram do Programa Nacional de Direitos Humanos de 1996, o qual demonstrou claramente o desejo do governo brasileiro de se inserir na ordem internacional no que concerne à proteção da pessoa humana.

O mencionado Diploma Legal traz em seu bojo o conceito de refugiado, nos seguintes termos:

Art. $1^{\circ}$ Será reconhecido como refugiado todo indivíduo que:

I - devido a fundados temores de perseguição por motivos de raça, religião, nacionalidade, grupo social ou opiniões politicas encontre-se fora de seu país de nacionalidade e não possa ou não queira acolher-se à proteção de tal pais;

II - não tendo nacionalidade e estando fora do país onde antes teve sua residência habitual, não possa ou não queira regressar a ele, em função das circunstâncias descritas no inciso anterior;

III - devido a grave e generalizada violação de direitos humanos, é obrigado a deixar seu país de nacionalidade para buscar refúgio em outro pais.

Percebe-se que a possibilidade de reconhecer um indivíduo como refugiado em função de grave e generalizada violação de direitos humanos não é consagrada pela Convenção de 1951, sendo 
uma inovação da lei brasileira inspirada em dois instrumentos regionais de proteção aos refugiados: a Convenção relativa aos Aspectos dos Refugiados Africanos, da Organização da Unidade Africana, de 1969, e a Declaração de Cartagena, da Organização dos Estados Americanos, de 1984. Com a inclusão deste dispositivo, a lei brasileira permite a proteção de um maior número de pessoas, ampliando seu espectro humanitário.

Desse modo, verifica-se que o Brasil, ao adotar a Lei 9.474/1997, teve como finalidade o melhor cumprimento das obrigações que lhe foram imputadas pela ratificação da Convenção de 1951 e do Protocolo de 1967, inclusive ampliando seu âmbito de proteção, o que torna imperiosa a adoção de procedimentos internosqueviabilizemseuexercíciopelosdestinatários, sob pena de se tornar letra morta.

Apregoa, ainda, a multicitada Lei que o refugiado gozará de direitos e estará sujeito aos deveres dos estrangeiros no Brasil, bem como poderá expressar sua vontade de solicitar reconhecimento como refugiado ${ }^{7}$, consagrando o princípio do non-refoulement, preceito norteador do Direito Internacional dos Refugiados, pelo qual "não se admite que o refugiado seja enviado de volta ao Estado de onde proveio e em que corre risco de perseguição ou de vida, ou seja, é a proibição de rechaço desse estrangeiro".

Portanto, é vedada a deportação do estrangeiro que manifeste interesse em receber o reconhecimento estatal de sua condição de refugiado, sobretudo quando aquela medida tenha o condão de entregá-lo ao Estado onde corra perigo de vida ou perseguição. Tal proibição de expulsão ou de rechaço já tinha sido consagrada na Convenção de 1951 (artigo 33):

1. Nenhum dos Estados Contratantes expulsará ou rechaçará, de forma alguma, um refugiado para as fronteiras dos territórios em que sua vida ou liberdade seja ameaçada em decorrência de sua raça, religião, nacionalidade, grupo social a que pertença ou opiniões políticas.

2. O benefício da presente disposição não poderá, todavia, ser invocado por um refugiado que por motivos sérios seja considerado um perigo à segurança do país no qual ele se encontre ou que, tendo sido condenado definitivamente por um crime ou delito particularmente grave, constitua ameaça para a comunidade do referido país.
Acerca do tema, assevera Paulo Henrique Gonçalves Portela9:

Com isso, é proibida a deportação do interessado no refúgio, mormente quando a medida possa levar a pessoa ao território de um Estado onde corra perigo, inclusive no caso de passageiros clandestinos ou irregulares, a menos que o potencial refugiado, 'por motivos sérios seja considerado um perigo à segurança do país no qual ele se encontre ou que, tendo sido condenado definitivamente por um crime ou delito particularmente grave, constitua ameaça para a comunidade do referido país'.

Saliente-se, ainda, que o artigo 10 do mesmo Diploma Legal preceitua que "a solicitação, apresentada nas condições previstas nos artigos anteriores, suspenderá qualquer procedimento administrativo ou criminal pela entrada irregular, instaurado contra o peticionário e pessoas de seu grupo familiar que o acompanhem".

Assim, da análise de todo o arcabouço normativo, mormente do direito internacional dos refugiados encampado pelo Brasil, inegável que não só os réus em processo penal ${ }^{10}$, mas qualquer indivíduo em território alienígena, ainda que sob a condição de refugiado, possui direito à assistência judiciária gratuita, a ser fornecida pelo Estado soberano onde se encontrar, preceito este incorporado pela ordem jurídica nacional.

\subsection{A necessidade de comunicar à Defensoria Pública o início do procedimento de deportação}

Neste ponto, para melhor visualização do momento em que se faz necessária a intimação da Defensoria Pública para atuar na defesa daquele que pleiteia o reconhecimento de sua condição de refugiado, revela-se fundamental uma rápida análise do procedimento administrativo da deportação, uma vez que os potenciais postulantes do status de refugiado são, em regra, estrangeiros que estão em situação irregular no país, sujeitos, assim, à deportação.

Nas palavras de Francisco Rezek ${ }^{11}$.

A deportação é uma forma de exclusão, do território nacional, daquele estrangeiro que aqui se encontre após uma entrada irregular - geralmente clandestina -, ou cuja estada tenha-se tornado irregular - quase sempre por excesso de prazo, ou 
por exercício de trabalho remunerado, no caso do turista.

A deportação está disciplinada na Lei 6.815/1980 (Estatuto do Estrangeiro) e no Decreto 86.715/1981, que a regulamenta, sendo o Departamento de Polícia Federal o órgão do Poder Executivo que possui atribuição para sua efetivação.

Sobre a deportação, dispõem os arts. 57 e 58 da Lei 6.815/1980, in verbis:

Art. 57. Nos casos de entrada ou estada irregular de estrangeiro, se este não se retirar voluntariamente do território nacional no prazo fixado em Regulamento, será promovida sua deportação.

$\$ 1^{\circ}$ Será igualmente deportado o estrangeiro que infringir o disposto nos artigos $21, \mathbb{\$} 2^{\circ}, 24,37$, $\$$ $2^{\circ}, 98$ a 101, $\$ \$ 1^{\circ}$ ou $2^{\circ}$ do artigo 104 ou artigo 105.

$\$ 2^{\circ}$ Desde que conveniente aos interesses nacionais, a deportaçãofar-se-áindependentemente da fixação do prazo de que trata o caput deste artigo.

Art. 58. A deportação consistirá na saída compulsória do estrangeiro.

Parágrafo único. A deportação far-se-á para o país da nacionalidade ou de procedência do estrangeiro, ou para outro que consinta em recebêlo.

Regulamentando os dispositivos legais supracitados, o Decreto 86.715/1981 delineou o procedimento da deportação nos seguintes termos:

Art. 98 - Nos casos de entrada ou estada irregular, o estrangeiro, notificado pelo Departamento de Polícia Federal, deverá retirar-se do território nacional:

I - no prazo improrrogável de oito dias, por infração ao disposto nos artigos $18,21, \mathbb{\$} 2^{\circ}, 24,26$, $\$ 1^{\circ}, 37, \$ 2^{\circ}, 64,98$ a $101, \$ \$ 1^{\circ}$ ou $2^{\circ}$ do artigo 104 ou artigos 105 e 125, Il da Lei 6.815, de 19 de agosto de 1980;

II - no prazo improrrogável de três dias, no caso de entrada irregular, quando não configurado o dolo.

$\$ 1^{\circ}$ - Descumpridos os prazos fixados neste artigo, o Departamento de Polícia Federal promoverá a imediata deportação do estrangeiro.

$\$ 2^{\circ}$ Desde que conveniente aos interesses nacionais, a deportaçãofar-se-áindependentemente da fixação dos prazos de que tratam os incisos I e II deste artigo.
Art. 99 - Ao promover a deportação, o Departamento de Polícia Federal lavrará termo, encaminhando cópia ao Departamento Federal de Justiça.

Verifica-se dos dispositivos legais e regulamentares acima transcritos a total ausência de balizas procedimentais que proporcionem uma sistemática prestação de assistência jurídica àqueles que ingressam irregularmente no país, malferindo, assim, o direito fundamental ao contraditório e à ampla defesa, assegurado pela Carta da República em seu art. $5^{\circ}, \mathrm{LV}$, bem como violando preceitos da Convenção de 1951 e do Protocolo de 1967.

Pode-se facilmente depreender que, sem a devida assistência, o estrangeiro muitas vezes sequer saberá quais requerimentos poderá formular perante as autoridades locais, já que, após ser notificado, terá no máximo apenas três dias para sair do país (a situação daquele que aporta clandestinamente no Brasil para pedir refúgio enquadra-se no inc. II do art. 98 do Dec. 86.715/1981), ao término do qual será retirado compulsoriamente pela Polícia Federal, podendo até mesmo ser deportado imediatamente, nos termos do $\$ 2^{\circ}$ acima transcrito.

Dessa forma, é imperiosa a necessidade de que em todos os procedimentos administrativos decorrentes da entrada irregular de estrangeiro no Brasil seja cientificado o órgão nacional oficialmente responsável pela prestação de assistência jurídica, sob pena de se fazer tábula rasa do direito de petição de refúgio (Lei 9.474/1997, art. $7^{\circ}$ ), assim como de todos os direitos assegurados na legislação aqui delineada.

Como é cediço, no âmbito do Estado brasileiro, a Defensoria Pública é órgão constitucionalmente destinado a prestar o serviço público essencial de assistência jurídica integral e gratuita, de forma permanente, nos termos do art. 134 da Constituição Federal.

Apesar de sua recente implementação, a Defensoria Pública tem importância crescente no resguardo ao contraditório e à ampla defesa, exemplo disso foi a edição da Lei 11.449/2007, que alterou a dicção do art. 306, $\mathbb{\$} 1^{\circ}$, do Código de Processo Penal, para os seguintes termos:

Art. 306, $\$ 1^{\circ}$ - Dentro em $24 \mathrm{~h}$ (vinte e quatro horas) depois da prisão, será encaminhado ao juiz competente o auto de prisão em flagrante 
acompanhado de todas as oitivas colhidas e, caso o autuado não informe o nome de seu advogado, cópia integral para a Defensoria Pública.

Com essa nova sistemática, a Defensoria Pública passou a atuar na defesa do indiciado desde a sua apresentação em estabelecimento policial ou penitenciário. Desde o início do inquérito policial a Defensoria Pública já é intimada a patrocinar sua defesa.

Ressalte-se que não só o hipossuficiente econômico faz jus à assistência da Defensoria Pública, mas também o hipossuficiente jurídico, a exemplo do que acontece na curadoria especial e na defesa dativa em processo criminal, onde o resguardo da ampla defesa e contraditório por si só justificam o patrocínio do Defensor Público.

Assim, quando um estrangeiro em situação irregular é encontrado pela Polícia Federal, poderá requerer junto ao Conare o pedido de refúgio em processo administrativo (Lei 9.474/97, art. $7^{\circ}$ ). Todavia, muitas vezes, esse pedido sequer chega a ser formulado devido à falta de conhecimento.

Com efeito, a única forma de harmonizar o procedimento administrativo sumário da deportação com o direito do estrangeiro de pedir refúgio ao Brasil é efetivar-se a intimação da Defensoria Pública da União tão logo um estrangeiro em situação irregular seja detido pela Polícia Federal.

A regular intimação da Defensoria Pública da União, nesse caso, é necessária para assegurar a efetividade de todos os direitos elencados pelas normas internacionais devidamente ratificadas pelo Brasil, dos quais, vale repisar, o direito de ser tratado juridicamente como um nacional, o que engloba a defesa em processo judicial e administrativo executada por um Defensor disponibilizado pelo Estado, caso ele mesmo não constitua advogado.

Importante frisar que esses direitos não se restringem aos processos judiciais, repercutindo também em processos administrativos. O pedido de refúgio junto ao Conare e o acompanhamento do processo administrativo em sede da Polícia Federal também são alcançados por essa proteção.

Todavia, verifica-se que no cotidiano tal expediente ainda não é regularmente adotado ante a falta de obrigatoriedade explícita em norma específica do procedimento de deportação, o que inegavelmente pode levar à supressão dos direitos dos alienígenas.

Não obstante, basta que se interprete o procedimento de acordo com os preceitos constitucionais e supralegais para restar inafastável a obrigatoriedade da comunicação ao órgão estatal de defesa desde a apresentação do estrangeiro à Polícia Federal.

Ora, obrigar-se perante a ordem internacional, bem como franquear a assistência jurídica aos estrangeiros irregulares em solo brasileiro, de nada adiantaria sem que a Defensoria Pública fosse intimada para conhecimento dos fatos, mesmo que o alienígena não tome a iniciativa de requerê-lo, pois não é incomum que desconheça a disponibilidade de tal serviço.

\section{Conclusão}

Como forma de instrumentalizar a concretização dos direitos humanos, a Lei Complementar 132, de 7 de outubro de 2009, atribui à Defensoria Pública a missão institucional de promovê-los, o que constituium avanço do Estado brasileiro na busca do adimplemento das obrigações assumidas perante a comunidade internacional, a exemplo do respeito ao devido processo legal aos que pretendem o reconhecimento da condição de refugiados.

A legislação de regência do procedimento de deportação, que prevêa sumária retirada do estrangeiro irregular do território nacional, deve passar por um processo de filtragem constitucional e ser interpretada em conjunto com o arcabouço jurídico que rege o instituto do refúgio.

Assim, à luz do que foi delineado, com fulcro nas normas internacionais ratificadas pelo Brasil e na própria legislação nacional, conclui-se ser imperiosa a intimação da Defensoria Pública da União, em todo país, para atuar na defesa dos estrangeiros, desde a sua apresentação à Polícia Federal.

(Endnotes)

1 Para Paulo Henrique Gonçalves Portela in: Direito Internacional Público e Privado. Salvador: Juspodivm, 2009, pp. 733-734: Um dos problemas que preocupam a sociedade internacional é a frequência com que pessoas, individualmente ou em grupo, abandonam o local onde vivem em decorrência de conflitos armados, desastres naturais ou perseguições de caráter político, ideológico ou religioso e se dirigem a outro Estado com o objetivo de ali encontrar a devida proteção. Tais pessoas normalmente são conhecidas como 
refugiados e necessitam de atenção especial, fazendo jus a normas peculiares de proteção enquanto permanecerem no território do ente estatal para onde se deslocaram.

2 PORTELA, Paulo Henrique Gonçalves. Direito Internacional Público e Privado. Salvador: Juspodivm, 2009, p. 734.

3 Ofício 206/2008 DELEMIG/SR/DPF/BA.

4. Art. $1^{\circ} \mathrm{A}$ Defensoria Pública é instituição permanente, essencial à função jurisdicional do Estado, incumbindo-lhe, como expressão e instrumento do regime democrático, fundamentalmente, a orientação jurídica, a promoção dos direitos humanos e a defesa, em todos os graus, judicial e extrajudicial, dos direitos individuais e coletivos, de forma integral e gratuita, aos necessitados, assim considerados na forma do inciso LXXIV do art. $5^{\circ}$ da Constituição Federal.

Art. 4 São funções institucionais da Defensoria Pública, dentre outras:

(...)

III - promover a difusão e a conscientização dos direitos humanos, da cidadania e do ordenamento jurídico;

(...)

VI - representar aos sistemas internacionais de proteção dos direitos humanos, postulando perante seus órgãos;

(...)

XVIII - atuar na preservação e reparação dos direitos de pessoas vítimas de tortura, abusos sexuais, discriminação ou qualquer outra forma de opressão ou violência, propiciando o acompanhamento e $\mathrm{o}$ atendimento interdisciplinar das vítimas;

5 JUBILUT, Liliana Lyra. O Direito Internacional dos Refugiados esua Aplicação no Ordenamento Jurídico Brasileiro. São Paulo: Método, 2007, pp. 181-182.

6 Em conclusão de julgamento, o Tribunal concedeu habeas corpus em que se questionava a legitimidade da ordem de prisão, por 60 dias, decretada em desfavor do paciente que, intimado a entregar o bem do qual depositário, não adimplira a obrigação contratual - v. Informativos 471, 477 e 498. Entendeu-se que a circunstância de o Brasil haver subscrito o Pacto de São José da Costa Rica, que restringe a prisão civil por dívida ao descumprimento inescusável de prestação alimentícia (art. $\left.7^{\circ}, 7\right)$, conduz à inexistência de balizas visando à eficácia do que previsto no art. $5^{\circ}$, LXVII, da CF ("não haverá prisão civil por dívida, salvo a do responsável pelo inadimplemento voluntário e inescusável de obrigação alimentícia e a do depositário infiel;"). Concluiu-se, assim, que, com a introdução do aludido Pacto no ordenamento jurídico nacional, restaram derrogadas as normas estritamente legais definidoras da custódia do depositário infiel. Prevaleceu, no julgamento, por fim, a tese do status de supralegalidade da referida Convenção, inicialmente defendida pelo Min. Gilmar Mendes no julgamento do RE 466343/SP, abaixo relatado. Vencidos, no ponto, os Ministros Celso de Mello, Cezar Peluso, Ellen Gracie e Eros Grau, que a ela davam a qualificação constitucional, perfilhando o entendimento expendido pelo primeiro no voto que proferira nesse recurso. O Min. Marco Aurélio, relativamente a essa questão, se absteve de pronunciamento. (HC 87585/TO, rel. Min. Marco Aurélio, 3/12/2008).

7 Art. $5^{\circ}$ : O refugiado gozará de direitos e estará sujeito aos deveres dos estrangeiros no Brasil, ao disposto nesta Lei, na Convenção sobre o Estatuto dos Refugiados de 1951 e no Protocolo sobre o Estatuto dos refugiados de 1967, cabendo-lhe a obrigação de acatar as leis, regulamentos e providências destinados à manutenção da ordem pública.

(...).

Art. $7^{\circ}$ : O estrangeiro que chegar ao território nacional poderá expressar sua vontade de solicitar reconhecimento como refugiado a qualquer autoridade migratória que se encontre na fronteira, a qual lhe proporcionará as informações necessárias quanto ao procedimento cabível. Bem como que em hipótese alguma será efetuada sua deportação para fronteira de território em que sua vida ou liberdade esteja ameaçada, em virtude de raça, religião, nacionalidade, grupo social ou opinião política.

8 DELL' OLMO, Florisbal de Souza. Curso de Direito Internacional Público. 2. ed. Rio de Janeiro: Forense, 2006, p.396.

9 PORTELA, Paulo Henrique Gonçalves. Direito Internacional Público e Privado. Salvador: Juspodivm, 2009, p. 735.

10 Atento à referida peculiaridade, na sessão plenária do dia 22 de outubro 2009, o Min. Celso de Melo chamou a atenção para a importância do tema: O Min. Celso de Mello salientou, quanto ao art. 36 da Convenção de Viena sobre Relações Consulares, que tal questão certamente deverá ser considerada por esta Corte em casos futuros se e quando ocorrer transgressão a essa norma de vital importância, a qual consubstancia uma prerrogativa que compõe hoje o universo conceitual dos direitos básicos da pessoa humana. Afirmou ter a impressão de que, em diversos procedimentos penais instaurados no Brasil contra súditos estrangeiros, as autoridades brasileiras não têm tido a percepção de que há uma obrigação imposta em tratado internacional multilateral, subscrito pelo Brasil e incorporado ao plano do direito positivo interno. Concluiu tratar-se, portanto, de uma matéria da qual o Tribunal deve se ocupar, especialmente no contexto da garantia do devido processo e da observância de direitos básicos que assistem a qualquerpessoae, em particular, aos estrangeiros quando efetivada a sua prisão por autoridades brasileiras. (Ext-1126, Inf. STF 564, 19 a 23/10/2009).

11 REZEK, Francisco. Direito Internacional Público. 11 ed. São Paulo: Saraiva, 2008, p. 195.

\section{Bibliografia}

DELl'OlmO, Florisbal de Souza. Curso de Direito Internacional Público. 2. ed. Rio de Janeiro: Forense, 2006.

JUBILUT, Liliana Lyra. O Direito Internacional dos Refugiados e sua Aplicação no Ordenamento Jurídico Brasileiro. São Paulo: Método, 2007.

PIOVESAN, Flávia. Direitos Humanos e o Direito Constitucional Internacional. $7^{\text {a }}$ ed. Ampl. e atual. São Paulo: Saraiva 2006.

PORTELA, Paulo Henrique Gonçalves. Direito Internacional Público e Privado. Salvador: Juspodivm, 2009.

REZEK, Francisco. Direito Internacional Público. 11 ed. São Paulo: Saraiva, 2008.

SARLET, Ingo Wolfgang. A Eficácia dos Direitos Fundamentais. Porto Alegre: Livraria do Advogado, 2006. 